Article

\title{
Food Crime: A Review of the UK Institutional Perception of Illicit Practices in the Food Sector
}

\begin{abstract}
Alice Rizzuti (D)
Department of Sociology, University of Essex, Wivenhoe Park, Colchester CO4 3SQ, UK; alice.rizzuti@essex.ac.uk

Received: 8 May 2020; Accepted: 30 June 2020; Published: 2 July 2020

check for updates

Abstract: Food offers highly profitable opportunities to criminal actors. Recent cases, from wine and meat adulteration to milk powder contaminations, have brought renewed attention to forms of harmful activities which have long occurred in the food sector. Despite several scandals over the last few decades, food has so far received scant criminological attention and the concept of food crime remains subject to different definitions. This article assesses regulations in the United Kingdom (UK) and UK authorities' official reports published between 2013 and 2018 through a review of academic literature published in English. It charts the evolution of the food crime concept, its various meanings, and different harmful activities associated with food crime, which originate from unlawful acts and omissions. This article also points out that further criminological research needs to address the definitional issue of food crime and inform a more integrated policy approach by considering activities beyond food fraud and the protection of food safety.
\end{abstract}

Keywords: food crime; food scandals; food safety

\section{Introduction}

Morally questionable, harmful and criminal practices, such as fraudulent activities of adulteration and misrepresentation or addition of chemicals, have a long history in the food sector (Phillips and French 1998; Walters 2010; South 2010; Croall 2013; Tourangeau and Fitzgerald 2020). Only within the last two decades has criminology considered these acts and omissions under the label of food crime.

Although food crime has a long history, it has come to public attention only after certain notable public scandals, such as the "horsemeat scandal," where, in 2013, cow meat (beef) across Europe was found to have been adulterated fraudulently with horsemeat. Despite the consumption of horsemeat not being harmful, the media presented the issue as a threat to human health. Notwithstanding the huge exposure to several food scandals, however, few people know what food crime means, and criminological interest in the problem has been scant. Practices, such as pollution caused by long-distance food transportation, the sale of adulterated food, the abuse of chemicals, and the exploitation of workers, as well as fraudulent trading behaviors committed by corporations and governments, have been considered more within discourses on food security and the violation of safety regulations rather than activities whose legal and criminological aspects are worth analyzing within a socio-legal perspective (Lang and Heasman 2004; Walters 2010). Moreover, little research has been carried out so far to investigate the institutional perception and policy response to food crime activities.

This article reviews the academic literature on the phenomenon of food crime and evaluates UK food regulations and official reports and documents published over the last five years by British public authorities active in the sector of food safety and crime. The specific timeframe that is chosen begins with the "horsemeat scandal", because this affair represents a turning point for policy attention to food-related criminal activities. This study charts the different conceptualizations of food crime adopted by the relevant academic literature in order to see if and how these perspectives match with the concept 
embraced by the UK authorities. This article maps the different types of activities under the food crime label, pointing to the definitional issues of the term, food crime, within UK policy documents. While these documents use food crime and food fraud interchangeably, a green criminological perspective (Croall 2013; Tourangeau and Fitzgerald 2020) allows for a broader analysis of the entire spectrum of harmful activities-beyond just that of food fraud-committed in the food sector.

The next section offers a brief outline of the specific context of the study and indicates the sources that have been used. The third section shows how the discourse around food crime has been connected historically to the concept of food security that has been considered by international agencies, such as the Food and Agriculture Organization (FAO) of the United Nations (UN), as well as within the green criminological literature. The fourth section reviews different conceptualizations of food crime, as formulated in the relevant literature, and the ways in which notions of food security and safety have shaped the understanding of food crime. Following this, the article charts UK institutional perceptions of illicit food-related activities and how enforcement authorities shape policies to protect the safety and authenticity of the food sector. Finally, the article concludes by returning to a discussion of the definitional issues surrounding the concept of food crime, suggesting that a green criminological perspective on food (Croall 2013; Gray 2018) can help to overcome these terminological and conceptual difficulties and can provide a guide for analyzing the harmful and criminal activities committed along the food supply chain.

\section{Methodology}

This article aims at analyzing the UK institutional approach to the issue of food crime. The backbone of the study has been the analysis of the conceptual and definitional issues surrounding food crime, taking into consideration its historical background. I adopted a qualitative methodology, which consisted of collecting and reviewing the relevant academic literature on food crime and the UK policy literature published after the "horsemeat scandal." Through documentary analysis, this article attempts to examine the British strategy on illicit activities in the food sector and the official reports and policy documents published by British public authorities active in the fields of food safety and food crime. The UK has been chosen because it was one of the main sites of the "horsemeat scandal," where investigations were conducted, and where actors were prosecuted and convicted (Lawrence 2013a, 2013b). Moreover, it was the first European country where the expression food crime appeared (Elliott 2014) and where the "horsemeat scandal" triggered the establishment of a specific agency (the National Food Crime Unit) created to tackle criminal practices inside the food sector.

For this study, I searched Google Scholar using the keywords "food crime" and "food fraud." I also located articles by examining the references of other connected articles and reports published in the field. The sources selected from the grey literature (see Table A1 in the Appendix A) reflect those that were issued by the UK authorities which are directly and indirectly relevant to the prevention and fight against food-related illicit activities during the aforementioned time period.

\section{The Precursors of the Food Crime Concept: From Food Security to Food Safety}

I begin this review of the concept of food crime by looking at how the food supply chain has been studied and linked historically to the conceptualization of food security. After the Second World War, in times of demographic and economic growth, a new agricultural system was developed in industrialized nations. Many countries, in fact, changed their agricultural techniques to achieve self-sufficient levels of production and avoid shortages of food for their growing populations. The modern agricultural system saw for the first time the use of chemicals, such as fertilizers and pesticides, and mechanization of the production of crops, such as corn, rice and wheat (Slater et al. 2014), which raised concerns about the safety of the practices applied. It was in this context, in 1974, that the World Food Conference first conceptualized the term food security to refer to "the availability and price stability of basic foodstuffs at the international and national level" (FAO 2006) —with increased rural 
deprivation and huge social inequalities in access to food contributing to unequal distribution of food and generating food insecurity (Slater et al. 2014).

It was not until the World Food Summits that took place in 1996 and in 2002, however, that the FAO formulated a more precise conceptualization of food security by considering the problems of distribution and food safety. These new understandings of food security, in fact, reflect the idea that "all people, at all times, have physical, social and economic access to sufficient, safe and nutritious food to meet their dietary needs and food preferences for an active and healthy life" (FAO 2006). The concept of food security is clearly addressed in the several reports and policy briefs on the state of food security and nutrition in the world annually published by FAO (for instance, see (FAO et al. 2018)). Furthermore, food security is explicitly linked to the right to food, which is protected by article 25 of the UN Declaration of Human Rights (United Nations 1948). This article considers the right to food in connection to the right of a standard of living adequate for health and well-being. Along the same line, the International Covenant on Economic, Social and Cultural Rights (United Nations 1966) recognizes the right of everyone to adequate food and pushes states to improve methods of production, conservation and distribution of food, with the aim of ensuring an equitable distribution of world food supplies. Similarly, the UN Committee on Economic, Social and Cultural Rights (CESCR) identifies the human right to adequate food as essential for the enjoyment of all human rights and links it to the fulfilment of human dignity (CESCR 1999). It continues by stressing that it is the duty of states to guarantee access to food and, in the context of social justice, to adopt specific economic, social and environmental policies to protect the right to adequate food. Interestingly, this document suggests the adoption of international and national strategies that could address critical issues of food security by taking into consideration all aspects of the food system including "the production, processing, distribution, marketing and consumption of safe food, as well as parallel measures in the fields of health, education, employment and social security" (CESCR 1999).

In academic literature, food security has been analyzed from many perspectives. For example, Brisman and South (2017) consider access to food in the context of global conflicts. Johnson and Walters (2014) describe how the stability-of and access-to food can be endangered by factors such as climate change and (related) natural disasters, as well as changes in economic, political and social situations. Indeed, a more robust notion of food security takes into consideration the stages of production, distribution and exchange (Ericksen 2008), and acknowledges connections between poverty and unequal distribution of food (Johnson and Walters 2014). Stack et al. (2013) underscores that for global food security, food must not just be available, but safe-an issue to which I turn next.

Food scandals that have occurred over the last thirty years have raised general concerns around the safety of the global food supply chain. The use of antibiotics in agriculture has been linked to antibiotic resistance in humans, and the abuse of genetically modified (GM) food is considered, by some, to pose a threat to public health and safety (Walters 2010). The UN World Health Organization (WHO) has devoted special attention to the concept of food safety by considering it an international security priority that is connected to "all the hazards, whether chronic or acute, that may make food injurious to consumer's health" (World Health Organization 2015). According to this perspective, food safety means "handling, storing and preparing food in order to prevent infection, and making sure that food keeps enough nutrients for a healthy diet." Endorsing this perspective, the FAO released a collection of guidelines and codes of practice with the aim of improving food safety policies and quality standards in order to protect human health (FAO and WHO n.d.). In the EU, the Green Paper on General Principles of Food Law (COM(97) 176 final 1997) (the "Green Paper") and the White Paper on Food Safety (COM(99) 0719 final 2000) state that consumers' health is a policy priority to develop by tracing the production and by monitoring the food supply chain in order to prevent any health risk (Smith et al. 2017; Manning and Soon 2016; Manacorda 2016). The Green Paper specifically claims that if a food business is caught in the act of selling a product that does not conform to the EU or national (UK) safety requirements provided, the firm may be liable under criminal or administrative law. In the UK, the Food Safety and Hygiene Regulations of 2013 are based on the European Regulation (EC) 
(n. 178/2002), which contains a general definition of food and food safety. More precisely, in order to protect food safety, article 14 of this regulation states that "it is necessary to adopt measures aimed at guaranteeing that unsafe food is not placed on the market and at ensuring that systems exist to identify and respond to food safety problems in order to ensure the proper functioning of the internal market and to protect human health." The regulation goes further by advising a wide perspective of food law that should cover a broad spectrum of provisions that could affect the safety of food. In protecting food safety, the law should consider all the stages of the food supply chain including production, manufacture, transport and distribution of food and feed, by addressing all those-also fraudulent-practices that could endanger the safety of the food system.

Moreover, the Food Safety Act 1990, the main legal framework regarding food safety in the UK, establishes that "consumers must have confidence that the food they buy and eat will be what they expect, will do them no harm and that they are protected from fraud" (Food Standards Agency 2009). The Food Safety Act applies to every food business, which must ensure not to include or remove anything in or from food or treat it in any way that can harm consumers' health, and this act establishes the offense of rendering food injurious to health (Section 7 of the Act). It also attempts to ensure the safety of food by prohibiting food which is not of the nature, substance or quality demanded (Section 14), and by rendering illegal the false or misleading description or presentation of food (Section 15).

In summary, food safety reflects attempts to protect public health and to safeguard the food supply chain from illicit practices. In many ways, then, the concept of food safety serves as an antecedent to that of food crime to which I turn next.

\section{Between Food Defense and Food Fraud: The Conceptualization of Food Crime in the Criminological Literature}

As this section will show, the criminological literature shapes food crime around the concept of food safety and the prevention of harms by intentional acts perpetrated in the food supply chain. Accordingly, this literature distinguishes food defense as policies and practices adopted against activities intended to harm consumers, and food safety encompassing policies and practices protecting the food system against unintentional contaminations of food products (Kastner et al. 2014; Manning and Soon 2016; Smith et al. 2017).

The concept of food crime has received limited attention within criminology, although many aspects of the food industry could be investigated under the lenses of criminality and deviance (Tourangeau 2016). By reviewing the literature, two main tendencies in the academic study of food crime can be distinguished. First, some researchers focus mainly on the organizational aspects of fraudulent activities in the food sector and the possible policy approaches in the prevention of these illicit practices. Second, some authors embrace critical approaches within green criminology and are interested in discourses around social and environmental harm, as well as social justice debates surrounding access to food.

According to the first strand of these discourses, fraudulent activities committed inside the food sector can be labeled as food fraud. Food fraud is a phenomenon that happens outside of the legitimate food sector and encompasses "the deliberate and intentional substitution, addition, tampering or misrepresentation of food, food ingredients or food packaging; or false or misleading statements made about a product for economic gain" (Spink and Moyer 2011).

Lord et al. (2017a) analyze the nature and organization of the behaviors that constitute fraud and consider the conditions that facilitate various types of fraud. They conceptualize food fraud as an endogenous phenomenon of the food system that consists of the "abuse or misuse of an otherwise legitimate transaction in which the actor undertakes practices of deception or dishonesty in order to avoid legal procedures and to gain profits or cause harm" (Lord et al. 2017a, p. 10). They argue that the legal definitions constructed from a policy point of view tend to focus on the mere manifestation of food fraud without actually understanding its nature, and the factors and conditions of its organization 
(Lord et al. 2017a). Hence, in a second paper, they suggest viewing food fraud through the lens of situational crime prevention and routine activity theory, identifying opportunities for food fraud, offenders' motivations and absences of capable guardianship (Lord et al. 2017b).

The second group of authors analyze the problem of illicit practices in the food system within a broader contextual perspective. From within green criminology, Croall $(2007,2013)$ is the first author to give a definition of food crime. According to her, food crime includes the "crimes that directly involve the processing, production and sale of food" (Croall 2013, p. 167). This conceptualization embraces the criminal activities involved in the local and global food trades that victimize consumers physically (by harming their health), psychologically (by eroding their trust) and/or financially. Cheng (2012) also describes food crime as a broad set of practices that violate laws, regulations and customs that should be respected by members of the food industry. Similarly, Gray (2018) claims the necessity of a food crime perspective that questions the concepts of crime and harm in relation to food issues and, hence, she includes a vast spectrum of illegal, criminal, harmful, unjust, unethical or immoral food-related practices. This conceptualization includes a wide range of illicit behaviors, including economic and physical harm to humans and non-humans involved in the food sector (Gray and Hinch 2015). Gray and Hinch (2015) argue that the criminological implications of food crime should be analyzed by investigating the criminogenic factors and the complexity of the contemporary food production system (Croall 2013; McDowell 2017). More specifically, Croall (2013) suggests a study of cultural factors, such as unethical consumption of unhealthy food that involves the exploitation of workers and environmental harms, and organizational factors, such as competition and corporate power. In the same way, Cheng (2012) claims that cheap capitalism is the criminological context that makes food crime possible. By cheap capitalism, he means a form of trade characterized by unsafe products and services, cheap prices and low quality, within a general condition of degraded business ethics where the only aim is to maximize profits.

According to this strand of the literature, food crime practices involve food fraud (e.g., intentional adulteration of food, counterfeiting food, watering down food), food poisoning (e.g., neglecting safety and handling food regulations, engaging in regulatory non-compliance), addition of chemicals (e.g., use of additives), food labeling (e.g., disregarding standards), non-criminalized food trade practices (e.g., anti-competition industry cartels and targeted food marketing), pricing (e.g., suspicious bargain offers aimed at deceiving the consumers), exploitation of labor in the agri-food sector (so-called "modern slavery"), financial crimes (e.g., tax and subsidy frauds, fraudulent handling of food paperwork), cruelty to animals and environmental harm due to food industry practices (e.g., overuse of pesticides and fertilizers) (Croall 2013; Gray 2018; Lang and Heasman 2004; Leon and Ken 2017; McDowell 2017; South 2010; Tourangeau and Fitzgerald 2020; Walters 2010).

If food crime incorporates a broad list of illicit activities directly and indirectly related to the food supply chain, then the above list is clearly not exhaustive. Essentially, while the first group of authors (Lord et al. 2017a, 2017b; Manning and Soon 2016; Spink and Moyer 2011; Van Ruth et al. 2018) acknowledge the wider harm of food crime activities and the role of corporate power, but focus primarily on the organization of food fraud, considering it a specific form of crime under the broader umbrella concept of food crime, by referring to a wide spectrum of criminal and quasi-criminal practices in the food sector, the second strand (Cheng 2012; Croall 2013; Gray 2018; Gray and Hinch 2015; McDowell 2017; Tourangeau and Fitzgerald 2020; Walters 2010) confronts the legal definitions of crime and poses questions around the concept of harm itself. Food crime is, therefore, perceived and conceptualized as a form of environmental harm and/or crime that affects food as a natural resource, where the modern food supply chain also raises issues of social (in)justice. In this way, this conceptualization of food crime is linked to food security and the necessity of equal access to sufficient food, but also to the concept of food safety, which focuses on whether food is safe to eat without the risk of illness or poisoning. 


\section{The Institutional Response to Food Crime in the UK Public Policy}

After the BSE (bovine spongiform encephalopathy or mad cow disease) outbreak at the beginning of the 1990s, governmental focus shifted to the protection of public health from contaminations of the food supply chain. Consequently, in 1998, the UK government decided to create a specific authority, the Food Standards Agency (FSA), in order to handle and promote food safety standards (Minister of Agriculture and Fisheries and Food 1998). In a similar way, the 2013 "horsemeat scandal" triggered the public debate around the safety of the sector. This time, because media and public attention centered on the illicit activities perpetrated inside the chain, the UK authorities' approach towards the issue changed. In other words, from this moment on, the UK public agencies and consumer organizations active in the protection of food started to acknowledge that harmful and criminal practices were widespread across the food supply chain and began to provide policy-oriented and working definitions of this nuanced phenomenon to overcome the lack of a legal definition.

In fact, the UK legislation does not encompass any juridical definition of food crime. Nevertheless, the UK National Food Crime Unit (NFCU) - a non-ministerial department established within the FSA after the "horsemeat scandal" - defines food crime as "dishonesty related to the production or supply of food, drink or animal feed which is either complex or likely to result in serious detriment to consumers, businesses or the overall public interest" (National Food Crime Unit 2016). The UK Food Law Code of Practice (Food Standards Agency 2017) specifies that food crime is a non-legal umbrella term used only to define the remit of the NFCU and clarifies that, in this context, food crime means "serious dishonesty which has a detrimental impact on the safety or the authenticity of food ( ... ) Food crime can be thought as a serious food fraud." As clarified in the document, the paradigm of seriousness is to be evaluated based on the facts of the specific food crime scenario and, hence, "on the likely level of detriment to an important interest such as the general public, a food business of the UK food industry" (Food Standards Agency 2017).

By considering activities that are perpetrated to deceive consumers for financial profits, the NFCU and the FSA identify three types of food crime: (1) "pure types," including serious criminal activities with the intent to endanger the safety and the authenticity of the food sector; (2) "indirect types," which have a detrimental impact as a consequence of other criminal activity; and (3) "cyber-enabled activities," facilitated or enabled by the use of the internet (National Food Crime Unit 2016). These authorities identify as criminal practices the following activities: diversion of waste products into the chain (e.g., animal waste used in products for human consumption); adulteration of food products (e.g., extraneous substances added to food or drink to reduce the quality); mispresentation of provenance, origin, quality or benefits (e.g., false declaration of geographic origin); substitution (e.g., replacing the whole product or parts of it without changing the overall characteristic); unlawful processing (e.g., using unapproved premises or unauthorized techniques); mispresentation of durability date (e.g., changing the label to sell expired products); theft (e.g., dishonestly appropriating food in order to make profits); and document fraud (e.g., using false product paperwork and documents) (National Food Crime Unit 2016). Moreover, the NFCU also identifies a form of so-called European distribution fraud that takes place when an EU-based food supplier is contacted by a fraudulent UK food business that places an order which is dispatched to a UK address without payment. This kind of fraud can cause wide risks for health because food safety, hygiene regulations and storage standards may not be followed by the fraudulent distributor (National Food Crime Unit 2016). The FSA and the Department for Environment, Food and Rural Affairs (DEFRA) also classify other indirect forms of threat that endanger the food sector by being harmful to food companies, such as extortion (e.g., threatening contamination of food products), espionage (e.g., competitors that seek commercial advantage by illegitimately accessing intellectual property), and cybercrime (e.g., credit card fraud in restaurants or hacking of agricultural technology) (PAS 96:2017 Guide to protecting and defending food and drink from deliberate attack, 2017). Except for the above-mentioned activities, the practices considered under the UK governmental conceptualization of food crime have a clear fraudulent characteristic. Indeed, the horsemeat scandal that triggered the regulatory reaction towards the illicit behaviors in the food sector is a case of food fraud. 
Food fraud is defined by the FSA and DEFRA as the act of "deliberately placing food on the market for financial gain, with the intention of deceiving the consumer." The FSA considers two main types of food fraud-(1) the sale of unfit and harmful food, and (2) the deliberate misdescription of food products (British Standards Institution et al. 2017). Because of the clamor of the "horsemeat scandal," DEFRA and the UK Department of Health commissioned a report on the integrity and assurance of food supply networks, known as the Elliot Review (Elliott 2014). The Elliot Review found that food fraud is committed to make profits with the intention of deceiving consumers, and it involves: deliberate and intentional substitution, addition, tampering or misrepresentation of food, food ingredients or food packaging; or false or misleading statements made about a product for economic gain. The report conceptualizes food crime by affirming that "it is a serious form of food fraud that no longer involves random acts by rogues within the food industry, but becomes an organized activity perpetrated by groups who knowingly set out to deceive, and/or injure, those purchasing a food product." By embracing this conceptualization, the NFCU Annual Strategic Assessment (2016) argues that "food fraud becomes food crime when the scale and potential impact of the activity is considered to be serious, (...) when the criminal activity has cross-regional, national or international reach, that there is significant risk to public safety, or that there is a substantial financial loss to consumers or businesses." Both perspectives suggest that when taking place as an organized activity perpetrated by groups who plan to maximize their profit, food fraud becomes serious, and, in this sense, constitutes food crime. Accordingly, the concept of food fraud has a central role within the governmental approach, to the extent that its conceptualization is the backbone of the food crime concept. The NFCU specifically establishes that food crime consists mainly of serious and complex food fraud, but acknowledges that it also addresses different forms of criminality that might indirectly affect the safety and/or authenticity of the food sector.

The perception of food crime adopted by the UK regulatory agencies does not seem to consider issues around food security in structuring food policies. The concept of food crime is shaped in large part by discourses of public health and food safety. In fact, UK food policies have focused mainly on ensuring that food is safe and free from intentional and unintentional contaminations, without taking into consideration the possible illicit profiles of the practices that happen inside the food sector beyond food fraud activities. Hence, the policy perspective and the theoretical conceptualization of food crime do not match.

As mentioned above, after the "horsemeat scandal", the UK government's attention has moved towards the harmful and illegal activities happening along the chain. The NFCU special unit has been created and food crime has been conceptualized as a form of serious dishonesty that can happen within the production or the supply of food, causing serious harm to consumers, businesses and the general public interest. The protection of public health and, consequently, the concern for food safety is still the main focus of the UK anti-food crime policy, but there is also increasing attention towards food authenticity and the protection of the UK food market's reputation. According to the analysis of the policy reports, the conceptualization of food crime adopted by regulatory bodies encompasses activities occurring in the stages of production, retail, logistics and disposal, which affect the safety and authenticity of the food product. Fraudulence is a recurring characteristic of the activities considered under this label of food crime and plays a central role in the governmental conceptualization of food. The Elliott Review explicitly acknowledges that the expressions "food fraud" and "food crime" are often used interchangeably (Elliott 2014). Moreover, food fraud emerges as food crime when it becomes organized and perpetrated by groups with the specific aim of deceiving and/or injuring consumers (Elliott 2014). The NFCU Annual Strategic Assessment adopts this perspective by asserting that food fraud is often an indicator of food crime (National Food Crime Unit 2016). In addition, the Elliott Review contends that cases in which fraudulently contaminated or altered foods cause severe illness or death are examples of food crime (Elliott 2014). The NFCU states that the term food crime is more capacious, encompassing forms of crimes that may have only an indirect impact on food safety and authenticity (National Food Crime Unit 2016). By looking at this policy conceptualization of food crime and at the types of practices considered within this perspective, the distinction between food 
fraud and food crime can be seen to rest on the level of seriousness of the fraud that is perpetrated. Furthermore, since food crime is considered as a serious and organized form of fraud, the concept of food crime derives directly from food fraud, which, in turn, is rooted in concerns around food safety.

This article shows that the definitional choices made in the formulation of UK policy appear underdeveloped because the distinction between food crime and food fraud seems blurred. Through a perspective that is based heavily on the protection of food safety, the policy approach aims to make the food market safe as well as reputable in the eyes of consumers. At the same time, there are other factors that should be considered in tackling criminal activities in the food sector. Food crime is, in fact, not only a matter of authenticity, fraud, and safety but also one encompassing issues of access, security, ethical consumption and environmental sustainability.

\section{Conclusions}

This article shows how the concept of food safety has been the foundation of a discourse on the issue of crimes involving food in policy documents and parts of the academic literature. Some academic studies specifically embrace the conceptualizations of food crime adopted by the public agencies and focus on developing strategies for industry and public investigators to prevent and address food fraud. Other research discusses, more generally, the harm and crimes that affect the food sector, questioning the legal definition of crime itself, and considering interests beyond the mere concept of food safety. One of these interests is food security. Indeed, this article shows how the theoretical concept of food crime originates in the concept of food security, which, therefore, represents the starting point of a discourse around the issue of illicit activities in the food sector. In this sense, this article also demonstrates that the safety-oriented policy perspective and the wide theoretical conceptualization of food crime do not match. Criminology could help widen policy approaches by considering activities beyond food fraud and outside the protection of food safety and authenticity. A green criminological perspective could be the most promising approach because it adopts a wider conceptualization of food crime that would address the definitional and conceptual problems around it. Such a conceptualization would allow us to go beyond legalistic definitions of crime established by the law, in order to include discourses around food harms, breaches of administrative law and their potential interactions with violations of criminal law.

Moreover, considering the socioeconomic and political changes that Brexit is likely to pose in the food sector, this article appears now more relevant than ever. On one hand, having entered the Brexit transition period, as the UK food legislation relies heavily on the EU food safety standards, the lack of a clear regulatory framework may open legal loopholes and gaps that criminal actors can exploit. Indeed, the risk of a no-deal between the UK and the EU persists and poses serious threats to both food safety and food security by leaving the UK food market more vulnerable and open to criminal actors (Grant 2019). The possible increase of tariffs will probably lead to an increase in prices of food products, with criminal actors starting to sell fraudulent goods at lower prices to hold costs down. Moreover, a no-deal Brexit may also endanger the UK's food security and cause food shortages that can be filled by illegitimate actors seeking profits. On the other hand, a possible trade agreement with the US would change and soften the safety standards that the UK has so far applied within the stricter EU framework; for example, US food safety policies permit the use of chemicals by allowing the sale of products such as chlorine-treated chicken or hormone-fed beef that are forbidden under the EU regulation ( $\mathrm{O}^{\prime}$ Carroll 2019). In this sense, despite the reassurances of the UK government, a trade deal with the US could push the UK to dilute and soften certain food regulations. At the same time, this dynamic could influence new policy definitions of food crime or crimes. More generally, a wider conceptualization of food crime constructed through the lens of green criminology would address harmful and criminal issues such as the respect towards social and dietary norms, environmental sustainability, improvement of food workers' rights and labour conditions.

A future study could clarify the relations between the wider conceptualization of food crime adopted within the literature and the concept of food safety that is central to food policies. Such an 
analysis could consider whether a more integrated approach to investigating and preventing food crimes is needed. Moreover, as already started by Lord and colleagues (2017a), further criminological research is needed to investigate the nature of the actors involved in criminal activities inside the food sector, and the possible incentives to commit food crimes.

Funding: This research received no external funding.

Conflicts of Interest: The author declares no conflict of interest.

\section{Appendix A}

Table A1. UK Public Authorities Policy Reports.

\section{UK Public Authorities Policy Reports}

Annual Report 2016-17, National Trading Standards, 2017

Consumer Harm Report 2016-17, National Trading Standards, 2017

Elliott Review into the Integrity and Assurance of Food Supply Networks-Final Report, Chris Elliot, 2014

Inquiry on Food Fraud on the Integrity of the Food System-Transcript of the Evidence Taken Before the Select Committee on the European Union Energy and Environment Sub-Committee, 2016

National Food Crime Unit Annual Strategic Assessment, National Food Crime Unit 2016

Food Law Code of Practice, Food Standards Agency (2017)

PAS96:2017 Guide to Protecting and Defending Food \& Drink from Deliberate Attack, DEFRA, FSA, BSI, 2017

The Development of the NFCU and the Decision to Proceed to Phase 2, FSA, 2018

The Food Safety Act 1990-A Guide for the Food Business, Food Standards Agency, 2009

The National Food Crime Unit-Update and Progress and Next Steps, FSA, 2017

Working Together to Tackle the Threat from Food Crime (FSA) - A Guide for the Industry to Working with the National Food Crime Unit, National Food Crime Unit 2017

\section{References}

Brisman, Avi, and Nigel South. 2017. Food, Crime, Justice and Security: (Food) Security for Whom? In Food Justice in US and Global Contexts: Bringing Theory and Practice Together. Edited by Ian Werkheiser and Zachary Piso. Cham: Springer, pp. 185-200. ISBN 978-3-319-57174-4.

British Standards Institution, Great Britain, Food \& Rural Affairs Department for Environment, Great Britain, and Food Standards Agency. 2017. Guide to Protecting and Defending Food and Drink from Deliberate Attack; British Standards Institution: Great Britain: Food \& Rural Affairs Department for Environment: Great Britain: London: Food Standards Agency. Available online: https://www.food.gov.uk/sites/default/files/media/doc ument/pas962017.pdf (accessed on 19 November 2018).

CESCR. 1999. General Comment No. 12: The Right to Adequate Food (Art. 11). Geneva: United Nations Committee on Economic, Social and Cultural Rights.

Cheng, Hongming. 2012. Cheap Capitalism: A Sociological Study of Food Crime in China. The British Journal of Criminology 52: 254-73. [CrossRef]

Croall, Hazel. 2007. Food Crime. In Issues in Green Criminology: Confronting Harms against Environments, Humanity and Other Animals. Edited by Piers Beirne and Nigel South. Ann Arbor: University of Michigan, Willan Pub, pp. 206-29. ISBN 978-1-84392-219-3.

Croall, Hazel. 2013. Food Crime. A Green Criminology Perspective. In Routledge International Handbook of Green Criminology. Edited by Nigel South and Avi Brisman. Abingdon: Routledge, pp. 167-83. ISBN 978-1-317-80899-2.

Elliott, Chris. 2014. Elliott Review into the Integrity and Assurance of Food Supply Networks-Final Report. A National Food Crime Prevention Framework. Available online: https://www.gov.uk/government/publicat ions/elliott-review-into-the-integrity-and-assurance-of-food-supply-networks-final-report (accessed on 19 November 2018).

Ericksen, Polly J. 2008. Conceptualizing Food Systems for Global Environmental Change Research. Global Environmental Change 18: 234-45. [CrossRef]

FAO. 2006. Food Security. Policy Brief 2. Available online: http://www.fao.org/fileadmin/templates/faoitaly/docu ments/pdf/pdf_Food_Security_Cocept_Note.pdf (accessed on 19 November 2018). 
FAO, and WHO. n.d. About CodexCODEXALIMENTARIUS. About Codex Alimentarius. Available online: http://www.fao.org/fao-who-codexalimentarius/about-codex/en/\#c453333 (accessed on 19 November 2018).

FAO, IFAD, UNICEF, WFP, and WHO. 2018. The State of Food Security and Nutrition in the World 2018. Building Climate Resilience for Food Security and Nutrition. Rome: FAO.

Food Standards Agency. 2009. The Food Safety Act 1990-A Guide for Food Businesses. Available online: https://www.food.gov.uk/sites/default/files/media/document/Food\%20standards\%20safety\%20ac t\%201990\%20PDF.pdf (accessed on 20 November 2018).

Food Standards Agency. 2017. Food Law Code of Practice. Available online: https://signin.riams.org/connect/revis ion/zmi2z/Environmental-Health/Food-Law-Code-of-Practice-England (accessed on 15 January 2019).

Grant, Katie. 2019. No-Deal Brexit Would Leave UK Vulnerable to Fresh Horsemeat Scandal. inews.co.uk. March 10. Available online: https://inews.co.uk/news/brexit/no-deal-brexit-food-fraud-another-horsemeat-scandal (accessed on 6 May 2019).

Gray, Allison D. 2018. A Food Crime Perspective. In A Handbook of Food Crime: Immoral and Illegal Practices in the Food Industry and What to Do about Them. Edited by Allison D. Gray and Ronald Owen Hinch. Bristol: Policy Press, pp. 11-26. ISBN 978-1-4473-3601-3.

Gray, Allison D., and Ronald Owen Hinch. 2015. Agribusiness, Governments and Food Crime: A Critical Perspective. In Green Harms and Crimes_Critical Criminology in a Changing World. Edited by Ragnhild Sollund. Basingstoke: Palgrave Macmillan, pp. 97-116. ISBN 978-1-137-45625-0.

Johnson, Hope, and Reece Walters. 2014. Food Security. In The Handbook of Security. Edited by Martin Gill. London: Palgrave Macmillan, pp. 404-426. ISBN 978-1-137-32327-9.

Kastner, Justin J., Abbey L. Nutsch, and Curtis L. Kastner. 2014. The Role of Food Safety in Food Security/Defense. In Food Safety and Food Security. Edited by John G. Voeller. Hoboken: Wiley, pp. 61-68. ISBN 978-1-118-65182-7.

Lang, Tim, and Michael Heasman. 2004. Food Wars: The Global Battle for Minds, Mouths, and Markets. London: Sterling: Earthscan, ISBN 978-1853837029.

Lawrence, Felicity. 2013a. HorsemeatScandal: Timeline. The Guardian. May 10 sec. UKnews. Available online: https://ww w.theguardian.com/uk/2013/may/10/horsemeat-scandal-timeline-investigation (accessed on 18 November 2018).

Lawrence, Felicity. 2013b. Horsemeat Scandal: The essential guide. The Guardian. February 15 sec. UK news. Available online: https://www.theguardian.com/uk/2013/feb/15/horsemeat-scandal-the-essential-gui de (accessed on 16 May 2019).

Leon, Kenneth S., and Ivy Ken. 2017. Food Fraud and the Partnership for a "Healthier" America: A Case Study in State-Corporate Crime. Critical Criminology 25: 393-410. [CrossRef]

Lord, Nicholas, Cecilia Juliana Flores Elizondo, and Jon Spencer. 2017a. The Dynamics of Food Fraud: The Interactions between Criminal Opportunity and Market (Dys)Functionality in Legitimate Business. Criminology \& Criminal Justice 17: 605-23. [CrossRef]

Lord, Nicholas, Jon Spencer, Jay Albanese, and Cecilia Flores Elizondo. 2017b. In Pursuit of Food System Integrity: The Situational Prevention of Food Fraud Enterprise. European Journal on Criminal Policy and Research 23: 483-501. [CrossRef]

Manacorda, Stefano. 2016. Synergies and Complementarities between the Directive 2012/29/UE and Other EU Legislation in the Fields of Environment Protection, Food Safety and Drugs Safety. In Rights of Victims, Challenges for Corporations. Project's First Findings. Victims and corporations Implementation of Directive 2012/29/EU for Victims of Corporate Crimes and Corporate Violence. Edited by Claudia Mazzucato. Milan: Università Cattolica del Sacro Cuore, pp. 109-31. ISBN 978-88-942229-1-3.

Manning, Louise, and Jan Mei Soon. 2016. Food Safety, Food Fraud, and Food Defense: A Fast Evolving Literature. Journal of Food Science 81: R823-34. [CrossRef] [PubMed]

McDowell, Tim C. 2017. The Complexity of the International Food Industry. International Journal of Society Systems Science 9: 1. [CrossRef]

Minister of Agriculture, and Fisheries and Food. 1998. The Food Standards Agency. A Force for Change. Available online: https:/assets.publishing.service.gov.uk/government/uploads/system/uploads/attachment_data/fil e/265718/fsa.pdf (accessed on 16 January 2019).

National Food Crime Unit. 2016. Food Crime. Annual Strategic Assessment. A 2016 Baseline. Available online: https://www.food.gov.uk/sites/default/files/media/document/fsa-food-crime-assessment-2016.pdf (accessed on 15 November 2018). 
O'Carroll, Lisa. 2019. Concern over Food Safety as US Seeks Greater Access to UK Markets. The Guardian. March 1 sec. Politics. Available online: https:/www.theguardian.com/politics/2019/mar/01/us-seeks-greater-access -to-uk-food-markets-after-brexit-trade-deal (accessed on 6 May 2019).

Phillips, Jim, and Michael French. 1998. Adulteration and Food Law, 1899-1939. Twentieth Century British History 9: 350-69. [CrossRef]

Slater, Rachel, Kay Sharp, and Steve Wiggins, eds. 2014. Food Security. In The Companion to Development Studies, 3rd ed. London and New York: Routledge, pp. 152-56. ISBN 978-1444167245.

Smith, Robert, Louise Manning, and Gerard McElwee. 2017. Critiquing the Inter-Disciplinary Literature on Food Fraud. International Journal of Rural Criminology 3: 250-70. [CrossRef]

South, Nigel. 2010. The Ecocidal Tendencies of Late Modernity: Polnational Crime, Social Exclusion, Victims and Rights. In Global Environmental Harm: Criminological Perspectives. Edited by Rob D. White. Cullompton: Willan, pp. 228-48. ISBN 978-1843927969.

Spink, John, and Douglas C. Moyer. 2011. Defining the Public Health Threat of Food Fraud. Journal of Food Science 76: R157-63. [CrossRef] [PubMed]

Stack, James P., Jacqueline Fletcher, and Lodovica M. Gullino. 2013. Climate Change and Plant Biosecurity: A New World Disorder? In Global Environmental Change: New Drivers for Resistance, Crime and Terrorism? Edited by Achim Maas, Balázs Bodó, Clementine Burnley, Irina Comardicea and Roger Roffey. Baden-Baden: Nomos, pp. 161-82. ISBN 978-3-8329-6894-6.

Tourangeau, Wesley. 2016. Criminology, Food, and Agriculture. In Encyclopedia of Food and Agricultural Ethics. Edited by Paul B. Thompson and David M. Kaplan. Dordrecht: Springer, pp. 1-7. ISBN 978-94-007-6167-4.

Tourangeau, Wesley, and Amy Fitzgerald. 2020. Food crime and green criminology. In Routledge International Handbook of Green Criminology, 2nd ed. Edited by Nigel South and Avi Brisman. Abingdon: Routledge.

United Nations. 1948. Universal Declaration of Human Rights. New York: United Nations.

United Nations. 1966. International Covenant on Economic, Social and Cultural Rights. New York: United Nations.

Van Ruth, Saskia M., Pieternel A. Luning, Isabelle C. J. Silvis, Yuzheng Yang, and Wim Huisman. 2018. Differences in Fraud Vulnerability in Various Food Supply Chains and Their Tiers. Food Control 84: 375-81. [CrossRef]

Walters, Reece. 2010. Crime, Political Economy and Genetically Modified Food. Abingdon and New York: Routledge, ISBN 978-0-203-84415-1.

World Health Organization. 2015. Food Safety: What You Should Know. SEARO. April 7. Available online: http: //www.searo.who.int/world_health_day/2015/whd-what-you-should-know/en/(accessed on 19 November 2018). 